Pacific Journal of Mathematics

WHITAKER CONSTANTS FOR ENTIRE FUNCTIONS OF 


\title{
WHITTAKER CONSTANTS FOR ENTIRE FUNCTIONS OF SEVERAL COMPLEX VARIABLES
}

\author{
JOHN K. SHAW
}

Let $f$ be an entire function of a single complex variable. The exponential type of $f$ is given by

$$
\tau(f)=\limsup _{n \rightarrow \infty}\left|f^{(n)}(0)\right|^{1 / n} .
$$

The Whittaker constant $W$ is defined to be the supremum of numbers $c$ having the following property: if $\tau(f)<c$ and each of $f, f^{\prime}, f^{\prime \prime}, \cdots$ has a zero in the $\operatorname{disc}|z| \leqq 1$, then $f \equiv 0$. The Whittaker constant is known to lie between .7259 and .7378 .

The present paper provides a definition and characterization of the Whittaker constant $\mathscr{W}_{n}$ for $n$ complex variables. The principle result of this characterization, which involves polynomial expansions of entire functions, is

$$
W>\mathscr{W}_{2} \geqq \mathscr{W}_{3} \geqq \cdots \text {. }
$$

To simplify notation, the presentation here is given for functions of two variables.

An exact determination of $W$ was obtained by M. A. Evgrafov in 1954 [3]. The determination involves the Gončarov polynomials, defined recursively by

$$
\begin{gathered}
G_{0}(z)=1 \\
G_{n}\left(z ; z_{0}, z_{1}, \cdots, z_{n-1}\right)=\frac{z^{n}}{n !}-\sum_{k=0}^{n-1} \frac{z_{k}^{n-k}}{(n-k) !} G_{k}\left(z ; z_{0}, z_{1}, \cdots, z_{k-1}\right) .
\end{gathered}
$$

Let

$$
H_{n}=\max \left|G_{n}\left(0 ; z_{0}, \cdots, z_{n-1}\right)\right|,
$$

where the maximum is taken over all sequences $\left\{z_{k}\right\}_{k=0}^{n-1}$ whose terms lie on $|z|=1$. Evgrafov proved that

$$
W=\left\{\limsup _{n \rightarrow \infty} H_{n}^{1 / n}\right\}^{-1} \text {. }
$$

An improvement of this result and further characterizations of $W$ were furnished by J. D. Buckholtz [1]. Using properties of the Gončarov polynomials, Buckholtz proved that

$$
(.4)^{1 / n} H_{n}^{-1 / n}<W \leqq H_{n}^{-1 / n},
$$

for $n=1,2,3, \cdots$. A consequence of these bounds is 


$$
W=\left\{\lim _{n \rightarrow \infty} H_{n}^{1 / n}\right\}^{-1}=\left\{\sup _{1 \leqq n<\infty} H_{n}^{1 / n}\right\}^{-1} .
$$

For an entire function $f$ (of two complex variables) the exponential type $\tau(f)$ is given by

$$
\tau(f)=\limsup _{m+n \rightarrow \infty}\left|f^{(m, n)}(0,0)\right|^{1 /(m+n)} .
$$

We define the Whittaker constant $\mathscr{V}^{\circ}$ to be the supremum of positive numbers $c$ having the following property: if $\tau(f)<c$ and each of $f^{(m, n)}(0 \leqq m<\infty, 0 \leqq n<\infty)$ has a zero in the poly $\operatorname{disc}\left\{\left(z_{1}, z_{2}\right)\right.$ : $\left.\left|z_{1}\right| \leqq 1,\left|z_{2}\right| \leqq 1\right\}$, then $f \equiv 0$. The bound $\mathscr{W} \geqq(\log 2) / 2$ was obtained by M. M. Dzrbasjan in 1957 [2].

The estimate furnished by Džrbašjan depends on a system of polynomials defined as follows. Let $\alpha=\left(\alpha_{p q}\right)$ and $\beta=\left(\beta_{p q}\right)$ be infinite matrices of complex numbers. The polynomials $A_{m, n}\left(z_{1}, z_{2} ; \alpha, \beta\right)$ are defined by the recursion formula

$$
\begin{gathered}
A_{0,0}\left(z_{1}, z_{2}\right)=1, \\
A_{r, s}\left(z_{1}, z_{2} ; \alpha, \beta\right)=\frac{z_{1}^{r} z_{2}^{s}}{r ! s !}-\sum_{\substack{p=0 \\
p+q<r+s}}^{s} \sum_{\substack{q=0 \\
p<r+s}} \frac{A_{p, q}\left(z_{1}, z_{2} ; \alpha, \beta\right) \alpha_{p q}^{r-p} \beta_{p q}^{s-q}}{(r-p) !(s-q) !}
\end{gathered}
$$

for $r, s=0,1,2, \cdots$. Note that $A_{r, s}$ depends only on those parameters $\alpha_{p q}$ and $\beta_{p q}$ for which $p+q<r+s$. Let

$$
H_{r, s}=\max \left|A_{r, s}(0,0 ; \alpha, \beta)\right|,
$$

where the maximum is taken over all matrices $\alpha$ and $\beta$ whose entries lie on $|z|=1$. We show that bound $H_{r s} \leqq(2 / \log 2)^{r+s}$ holds for all $r$ and $s$. The justifies the definition

$$
H=\sup _{1 \leqq r, s<\infty} H_{r, s}^{1 /(r+s)} .
$$

We prove the following expansion theorem.

Theorem 1. Suppose $f$ is entire and $\tau(f)<1 / H$. If $\alpha$ and $\beta$ are infinite complex matrices whose entries lie in $|z| \leqq 1$, then

$$
f\left(z_{1}, z_{2}\right)=\sum_{m=0}^{\infty} \sum_{n=0}^{\infty} f^{(m, n)}\left(\alpha_{m n}, \beta_{m n}\right) A_{m, n}\left(z_{1}, z_{2} ; \alpha, \beta\right)
$$

for all $\left(z_{1}, z_{2}\right)$.

The following result shows that the expansion constant $1 / H$ is as large as possible.

THEOREM 2. There exists an entire function $F$, with $\tau(F)=$ 
$1 / H$, such that each of $F^{(m, n)}(0 \leqq m<\infty, 0 \leqq n<\infty)$ has a zero in the polydisc $\left\{\left|z_{1}\right| \leqq 1,\left|z_{2}\right| \leqq 1\right\}$.

Theorem 1 and Theorem 2 will be proved in $\S 3$. We note, however, that the following result is an easy consequence of Theorems 1 and 2.

\section{Corollary 1. $\mathscr{\mathscr { W }}=1 / H$.}

Therefore, each of the numbers $H_{m, n}^{-1 /(m+n)}$ is an upper bound for $\mathscr{W}$. In particular, $\mathscr{W} \leqq 1 / \sqrt{H_{1,1}}=1 / \sqrt{3}$. In comparing this with the bound $W>.7259$, one sees that $\mathscr{W}<W$.

2. The Polynomials $A_{m, n}$, Let $f$ be an entire function and let $\alpha$ and $\beta$ be infinite complex matrices. Writing (1.4) in the form

$$
\frac{z_{1}^{r} z_{2}^{s}}{r ! s !}=\sum_{p=0}^{r} \sum_{q=0}^{s} \frac{A_{p, q}\left(z_{1}, z_{2} ; \alpha, \beta\right) \alpha_{p q}^{r-p} \beta_{p q}^{s-q}}{(r-p) !(s-q) !}
$$

we obtain the formal expansion

$$
\begin{aligned}
& f\left(z_{1}, z_{2}\right)=\sum_{r=0}^{\infty} \sum_{s=0}^{\infty} f^{(r, s)}(0,0) \frac{z_{1}^{r} z_{2}^{s}}{r ! s !} \\
= & \sum_{r=0}^{\infty} \sum_{s=0}^{\infty} f^{(r, s)}(0,0)\left\{\sum_{p=0}^{r} \sum_{q=0}^{s} \frac{A_{p, q}\left(z_{1}, z_{2} ; \alpha, \beta\right) \alpha_{p q}^{r-p} \beta_{p q}^{s-q}}{(r-p) !(s-q) !}\right\} \\
= & \sum_{p=0}^{\infty} \sum_{q=0}^{\infty} A_{p, q}\left(z_{1}, z_{2} ; \alpha, \beta\right)\left\{\sum_{r=p}^{\infty} \sum_{s=q}^{\infty} f^{(r, s)}(0,0) \frac{\alpha_{p q}^{r-p} \beta_{p q}^{s-q}}{(r-p) !(s-q) !}\right\} \\
= & \sum_{p=0}^{\infty} \sum_{q=0}^{\infty} f^{(p, q)}\left(\alpha_{p q}, \beta_{p q}\right) A_{p, q}\left(z_{1}, z_{2} ; \alpha, \beta\right),
\end{aligned}
$$

which holds whenever the interchange in the order of summation can be justified. In particular, (2.1) holds if $f$ is a polynomial and yields considerable information when $f$ is taken to be one of the polynomials $A_{m, n}$.

LEMma 1. If $\lambda$ is a complex number, then

$$
A_{m, n}\left(\lambda z_{1}, \lambda z_{2} ; \lambda \alpha, \lambda \beta\right)=\lambda^{m+n} A_{m, n}\left(z_{1}, z_{2} ; \alpha, \beta\right),
$$

where $\lambda \alpha$ denotes matrix scalar multiplication. Furthermore,

$$
A_{m, n}\left(\alpha_{00}, \beta_{00} ; \alpha, \beta\right)=0 \quad(m+n>0) .
$$

Proof. We will prove (2.2) using mathematical induction. The proof of (2.3) is similar. If $m+n=0$, the result is clear. Suppose 
$N$ is a positive integer and (2.2) holds for the polynomials $A_{p, q}$ with $p+q<N$. If $r$ and $s$ are nonnegative integers such that $r+s=N$, then

$$
\begin{aligned}
& A_{r, s}\left(\lambda z_{1}, \lambda z_{2} ; \lambda \alpha, \lambda \beta\right) \\
= & \lambda^{r+s} \frac{z_{1}^{r} z_{2}^{s}}{r ! s !}-\sum_{\substack{p=0 \\
p+q<r+s}}^{s} \frac{A_{p, q}\left(\lambda z_{1}, \lambda z_{2} ; \lambda \alpha, \lambda \beta\right)\left(\lambda \alpha_{p q}\right)^{r-p}\left(\lambda \beta_{p q}\right)^{s-q}}{(r-p) !(s-q) !} \\
= & \lambda^{r+s} \frac{z_{1}^{r} z_{2}^{s}}{r ! s !}-\lambda^{r+s} \sum_{\substack{p=0 \\
p=0<r<0}}^{s} \frac{A_{p q}\left(z_{1}, z_{2} ; \alpha, \beta\right) \alpha_{p q}^{r-p} \beta_{p q}^{s-q}}{(r-p) !(s-q) !} \\
= & \lambda^{r+s} A_{r, s}\left(z_{1}, z_{2} ; \alpha, \beta\right)
\end{aligned}
$$

and this completes the proof.

Let $\alpha=\left(\alpha_{p q}\right)_{p, q=0}^{\infty}$ be an infinite complex matrix. If $j$ and $k$ are nonnegative integers, we denote by $R_{j_{k}}$ the operator which transforms $\alpha$ into

$$
R_{j k}(\alpha)=\left(\alpha_{p+j q+k}\right)_{p, q=0}^{\infty} \text {. }
$$

Lemma 2. If $m+n>0, j \leqq m$ and $k \leqq n$, then

$$
A_{m, n}^{(j, k)}\left(z_{1}, z_{2} ; \alpha, \beta\right)=A_{m-j n-k}\left(z_{1}, z_{2} ; R_{j k}(\alpha), R_{j_{k}}(\beta)\right) \text {. }
$$

Proof. By direct computation, $A_{10}\left(z_{1}, z_{2} ; \alpha, \beta\right)=z_{1}-\alpha_{00}$ and

$$
A_{01}\left(z_{1}, z_{2} ; \alpha, \beta\right)=z_{2}-\beta_{00},
$$

so the result is clear if $m+n=1$. Proceeding inductively, let $N$ be a positive integer and suppose the proposition is true for the polynomials $A_{p q q}$ with $p+q<N$. If $r$ and $s$ are nonnegative integers such that $r+s=N$, then for $j \leqq r$ and $k \leqq s$ we have

$$
\begin{aligned}
& A_{r, s}^{(j, k)}\left(z_{1}, z_{2} ; \alpha, \beta\right) \\
& =\frac{z_{1}^{r-j} z_{2}^{s-k}}{(r-j) !(s-k) !}-\sum_{\substack{p=0 \\
p+q<r+s}}^{r} \sum_{\substack{q=0 \\
p+q}}^{s} \frac{A_{p, q}^{(j, k)}\left(z_{1}, z_{2} ; \alpha, \beta\right) \alpha_{p q}^{r-p} \beta_{p q}^{s-q}}{(r-p) !(s-q) !} \\
& =\frac{z_{1}^{r-j} z_{2}^{s-k}}{(r-j) !(s-k) !}-\sum_{\substack{p=j \\
p+q<r+s}}^{r} \sum_{\substack{q=k \\
p+q}}^{s} \frac{A_{p-j q-k}\left(z_{1}, z_{2} ; R_{j k}(\alpha), R_{j k}(\beta)\right) \alpha_{p q}^{r-p} \beta_{p q}^{s-q}}{(r-p) !(s-q) !} \\
& =\frac{z_{1}^{r-j} z_{2}^{s-k}}{(r-j) !(s-k) !}-\sum_{\substack{p=0 \\
p+q<r-j+s-k}}^{r-j} \sum_{\substack{q=0 \\
s-k}} \frac{A_{p q}\left(z_{1}, z_{2} ; R_{j k}(\alpha), R_{j k}(\beta)\right) \alpha_{p+j, q+k}^{r-j-p} \beta_{p+j, q+k}^{s-k-q}}{(r-j-p) !(s-k-q) !} \\
& =A_{r-j, s-k}\left(z_{1}, z_{2} ; R_{j k}(\alpha), R_{j k}(\beta)\right) \text {, }
\end{aligned}
$$

and this completes the proof.

Lemma 2 and the expansion (2.1) provide a useful expression for the polynomials $A_{m, n}$. Replacing $\alpha$ and $\beta$ by $\gamma$ and $\delta$, respectively, 
and applying (2.1) to the polynomial $A_{r s}\left(z_{1}, z_{2} ; \alpha, \beta\right)$, we have

$$
\begin{aligned}
& A_{r, s}\left(z_{1}, z_{2} ; \alpha, \beta\right) \\
= & \sum_{p=0}^{r} \sum_{q=0}^{s} A_{r, s}^{(p, q)}\left(\gamma_{p q}, \delta_{p q} ; \alpha, \beta\right) A_{p q}\left(z_{1}, z_{2} ; \gamma, \delta\right) \\
= & \sum_{p=0}^{r} \sum_{q=0}^{s} A_{p, q}\left(z_{1}, z_{2} ; \gamma, \delta\right) A_{r-p, s-q}\left(\gamma_{p q}, \delta_{p q} ; R_{p q}(\alpha), R_{p q}(\beta)\right) .
\end{aligned}
$$

If each of $\gamma$ and $\delta$ is the zero matrix, it is easy to see that

$$
A_{p, q}\left(z_{1}, z_{2} ; \gamma, \delta\right)=\frac{z_{1}^{p} z_{2}^{q}}{p ! q !}
$$

In this case (2.5) yields

$$
A_{r, s}\left(z_{1}, z_{2} ; \alpha, \beta\right)=\sum_{p=0}^{r} \sum_{q=0}^{s} A_{r-p s-q}\left(0,0 ; R_{p q}(\alpha), R_{p q}(\beta)\right) \frac{z_{1}^{p} z_{2}^{q}}{p ! q !} .
$$

Let $m$ and $n$ be integers such that $0 \leqq m \leqq r, 0 \leqq n \leqq s$, and $m+n>0$. In (2.5) choose

$$
\gamma_{p q}=\left\{\begin{array}{l}
0, \text { if } p \geqq m \text { and } q \geqq n \\
\alpha_{p q}, \text { otherwise }
\end{array}\right.
$$

and

$$
\delta_{p q}=\left\{\begin{array}{l}
0, \text { if } p \geqq m \text { and } q \geqq n \\
\beta_{p q}, \text { otherwise }
\end{array}\right.
$$

In view of (2.3) we have

$$
\begin{aligned}
& A_{r, s}\left(z_{1}, z_{2} ; \alpha, \beta\right) \\
= & \sum_{p=m}^{r} \sum_{q=n}^{s} A_{p q}\left(z_{1}, z_{2} ; \gamma, \delta\right) A_{r-p s-q}\left(0,0 ; R_{p q}(\alpha), R_{p q}(\beta)\right) .
\end{aligned}
$$

More generally, we define the operator $P_{j_{k}}$ as follows. If $j+k>0$, then $P_{j k}(\alpha)$ is the matrix $\left(a_{p q}\right)$, where

$$
a_{p q}=\left\{\begin{array}{l}
0, \text { if } p \geqq j \text { and } q \geqq k \\
\alpha_{p q}, \text { otherwise } .
\end{array}\right.
$$

Then (2.7) becomes

$$
\begin{aligned}
& A_{r, s}\left(z_{1}, z_{2} ; \alpha, \beta\right) \\
& =\sum_{p=m}^{r} \sum_{q=n}^{s} A_{p, q}\left(z_{1}, z_{2} ; P_{m n}(\alpha), P_{m n}(\beta)\right) A_{r-p s-q}\left(0,0 ; R_{p q}(\alpha), R_{p q}(\beta)\right) \text {. }
\end{aligned}
$$

Equation (2.8) may be regarded as a separation of variables formula, in the following sense. If $p \geqq m$ and $q \geqq n$, then $R_{p q}(\alpha)$ depends on the parameters $\alpha_{j k}$, where $j \geqq m$ and $k \geqq m$, and $P_{m n}(\alpha)$ depends 
on the parameters $\alpha_{j k}$, where $j<m$ or $k<n$. The usefulness of (2.8) is seen in the next lemma.

Lemma 3. If $0 \leqq m \leqq r$ and $0 \leqq n \leqq s$, then

$$
H_{r, s} \geqq H_{m, n} H_{r-m, s-n} \text {. }
$$

Proof. If $m+n=0$, the result is trivial. Suppose $m+n>0$ and choose matrices $\alpha$ and $\beta$, whose entries lie on $|z|=1$, such that

$$
H_{m, n}=\left|A_{m, n}\left(0,0 ; P_{m n}(\alpha), P_{m n}(\beta)\right)\right|
$$

and

$$
H_{r-m, s-n}=\mid A_{r-m, s-n}\left(0,0 ; R_{m n}(\alpha), R_{m n}(\beta)\right) .
$$

For each complex number $\lambda$, define the matrices $\gamma=\gamma(\lambda)$ and $\delta=\delta(\lambda)$ by

$$
\gamma_{p q}=\left\{\begin{array}{l}
\alpha_{p q}, \text { if } p \geqq m \text { and } q \geqq n \\
\lambda \alpha_{p q}, \text { otherwise }
\end{array}\right.
$$

and

$$
\widehat{o}_{p q}=\left\{\begin{array}{l}
\beta_{p q}, \text { if } p \geqq m \text { and } q \geqq n \\
\lambda \beta_{p q}, \text { otherwise } .
\end{array}\right.
$$

By (2.8) and (2.2),

$$
\begin{aligned}
& A_{r, s}(0,0 ; \gamma, \delta) \\
= & \sum_{p=m}^{r} \sum_{q=n}^{s} A_{p, q}\left(0,0 ; P_{m n}(\gamma), P_{m n}(\delta)\right) A_{r-p, s-q}\left(0,0 ; R_{p q}(\gamma), R_{p q}(\delta)\right) \\
= & \sum_{p=m}^{r} \sum_{q=n}^{s} \lambda^{p+q} A_{p, q}\left(0,0 ; P_{m n}(\alpha), P_{m n}(\beta)\right) A_{r-p, s-q}\left(0,0 ; R_{p q}(\alpha), R_{p q}(\beta)\right) \\
= & \lambda^{m+n} Q(\lambda),
\end{aligned}
$$

where $Q(\lambda)$ is a polynomial in $\lambda$. Since

$$
H_{r, s} \geqq \max _{|\lambda|=1}\left|A_{r, s}(0,0 ; \gamma, \delta)\right|=\max _{|\lambda|=1}|Q(\lambda)| \geqq|Q(0)|
$$

and

$$
\begin{aligned}
|Q(0)| & =\left|A_{m, n}\left(0,0 ; P_{m n}(\alpha), P_{m n}(\beta)\right)\right|\left|A_{r-m, s-n}\left(0,0 ; R_{m n}(\alpha), R_{m n}(\beta)\right)\right| \\
& =H_{m, n} H_{r-m, s-n},
\end{aligned}
$$

we have

$$
H_{r, s} \geqq H_{m, n} H_{r-m, s-n} \text {. }
$$


Lemma 4. There is an infinite subsequence $S=\left\{\left(m_{j}, n_{j}\right): j=\right.$ $1,2,3, \cdots\}$ such that

$$
H=\lim _{j \rightarrow \infty} H_{m_{j}, n_{j}}^{1 /\left(m_{j}+n_{j}\right)}
$$

and

$$
H_{m_{j}, n_{j}}^{1 /\left(m_{j}+n_{j}\right)} \geqq H_{p, q}^{1 /(p+q)}
$$

for all $p$ and $q$ such that $p+q \leqq m_{j}+n_{j}$.

Proof. If there is a pair $(r, s)$ such that $H_{r, s}^{1 /(r+s)}=H$, then (2.9) implies

$$
H \geqq H_{j r, j s}^{1 / j(r+s)} \geqq\left(H_{r, s}^{j}\right)^{1 / j(r+s)}=H_{r, s}^{1 /(r+s)}=H
$$

for $j=1,2,3, \cdots$. In this case we take $S=\{(j r, j s): j=1,2,3, \cdots\}$.

Suppose, on the other hand, that $H>H_{r, s}^{1 / r+s)}$ for all $r$ and $s$. For each positive integer $k$, let

$$
T_{k}=\max _{p+q=k} H_{p, q}^{1 /(p+q)} .
$$

Then $T_{k}<H(1 \leqq k<\infty)$ and $\sup _{1 \leqq k<\infty} T_{k}=H$. We can therefore find a subsequence $\left\{T_{k_{j}}\right\}_{j=1}^{\infty}$ with the properties that

$$
\lim _{j \rightarrow \infty} T_{k_{j}}=H
$$

and

$$
T_{k_{j}}>T_{n}
$$

for $n<k_{j}$. For each $j$, choose integers $m_{j}$ and $n_{j}$ such that $m_{j}+n_{j}=k_{j}$ and $T_{k_{j}}=H_{m_{j}, n_{j}}^{1 /\left(m_{j}+n_{j}\right)}$, and let $S=\left\{\left(m_{j}, n_{j}\right): j=1,2,3, \cdots\right\}$. This completes the proof of the lemma.

CoRollary 2. $\quad H=\limsup _{m+n \rightarrow \infty} H_{m, n}^{1 /(m+n)}$.

LEMMA 5. For each pair of nonnegative integers $(m, n)$ we have

$$
H_{m, n} \leqq(2 / \log 2)^{m+n} \text {. }
$$

Proof. The result is trivial if $m+n=0$. Let $N$ be a positive integer and suppose (2.10) holds whenever $m+n<N$. Let $r$ and $s$ be nonnegative integers such that $r+s=N$. The defining relations (1.4) imply 


$$
\begin{aligned}
& H_{r, s} \leqq \sum_{\substack{p=0 \\
p+q<r+s}}^{r} \sum_{q=0}^{s} \frac{H_{p q}}{(r-p) !(s-q) !}=\sum_{\substack{j=0 \\
j+k>0}}^{r} \sum_{\substack{k=0 \\
j+k}}^{s} \frac{H_{r-j . s-k}}{j ! k !} \\
& \leqq \sum_{\substack{j=0 \\
j+k>0}}^{r} \sum_{\substack{k=0 \\
s}} \frac{(2 / \log 2)^{r-j+s-k}}{j ! k !} \\
& =(2 / \log 2)^{r+s}\left\{\sum_{j=0}^{r} \sum_{k=0}^{s} \frac{((\log 2) / 2)^{j+k}}{j ! k !}-1\right\} \\
& <(2 / \log 2)^{r+s}\left\{\sum_{j=0}^{\infty} \sum_{k=0}^{\infty} \frac{((\log 2) / 2)^{j+k}}{j ! k !}-1\right\} \\
& =(2 / \log 2)^{r+s}\left\{e^{(2 \log 2) / 2}-1\right\}=(2 / \log 2)^{r+s} \text {. }
\end{aligned}
$$

Corollary $3 . \quad H \leqq(2 / \log 2)$.

Note that this result, together with Corollary 1, implies Džrbašjan's estimate $\mathscr{W} \geqq(\log 2) / 2$.

3. Main Results. Let

$$
M\left(z_{1}, z_{2}\right)=\sum_{p=0}^{\infty} \sum_{q=0}^{\infty} \frac{1}{H_{p, q}} \frac{z_{1}^{p} z_{2}^{q}}{p ! q !} .
$$

Note that $M\left(z_{1}, z_{2}\right)$ is an entire function of exponential type 1 or less. Suppose $\alpha$ and $\beta$ have entries lying in $|z| \leqq 1$. By (2.6),

$$
A_{r, s}\left(z_{1}, z_{2} ; \alpha, \beta\right)=\sum_{p=0}^{r} \sum_{q=0}^{s} A_{r-p, s-q}\left(0,0 ; R_{p q}(\alpha), R_{p q}(\beta)\right) \frac{z_{1}^{p} z_{2}^{q}}{p ! q !} .
$$

Since

$$
\left|A_{r-p, s-q}\left(0,0 ; R_{p q}(\alpha), R_{p q}(\beta)\right)\right| \leqq H_{r-p, s-q} \leqq H_{r, s} / H_{p, q},
$$

it follows that the coefficients of $A_{r s}$ are bounded by the respective coefficients of $H_{r, s} M\left(z_{1}, z_{2}\right)$; i.e., $A_{r s}$ is majorized by $H_{r, s} M\left(z_{1}, z_{2}\right)$. In particular,

$$
\left|A_{r, s}\left(z_{1}, z_{2} ; \alpha, \beta\right)\right| \leqq H_{r, s} M\left(\left|z_{1}\right|,\left|z_{2}\right|\right)
$$

We are now ready to prove Theorem 1 .

Suppose $f$ is an entire function, with $\tau(f)<1 / H$, and suppose $\alpha$ and $\beta$ are matrices whose entries lie in $|z| \leqq 1$. In order to justify the expansion (2.1) we show that the series

$$
\sum_{r=0}^{\infty} \sum_{s=0}^{\infty}\left|f^{(r, s)}(0,0)\right| \sum_{p=0}^{r} \sum_{q=0}^{s} \frac{\left|A_{p . q}\left(z_{1}, z_{2} ; \alpha, \beta\right)\right|}{(r-p) !(s-q) !}
$$

is convergent. Equation (3.1) implies 


$$
\left|A_{p, q}\left(z_{1}, z_{2} ; \alpha, \beta\right)\right| \leqq H_{p q} M\left(\left|z_{1}\right|,\left|z_{2}\right|\right) \leqq H_{r s} M\left(\left|z_{1}\right|,\left|z_{2}\right|\right) / H_{r-p s-q} ;
$$

therefore

$$
\begin{aligned}
& \sum_{p=0}^{r} \sum_{q=0}^{s} \frac{\left|A_{p q}\left(z_{1}, z_{2} ; \alpha, \beta\right)\right|}{(r-p) !(s-q) !} \\
\leqq & H_{r s} M\left(\left|z_{1}\right|,\left|z_{2}\right|\right) \sum_{p=0}^{r} \sum_{q=0}^{s} \frac{1}{H_{r-p s-q}(r-p) !(s-q) !} \\
< & H_{r s} M\left(\left|z_{1}\right|,\left|z_{2}\right|\right) M(1,1) .
\end{aligned}
$$

The series (3.2) is therefore convergent provided that

$$
\sum_{r=0}^{\infty} \sum_{s=0}^{\infty}\left|f^{(r, s)}(0,0)\right| H_{r s}
$$

converges. Choose $\varepsilon>0$ such that $\tau(f)+\varepsilon<1 / H$ and let $N$ be a positive integer such that $r+s \geqq N$ implies

$$
\left|f^{(r, s)}(0,0)\right|^{1 /(r+s)}<\tau(f)+\varepsilon .
$$

Then

$$
\sum_{r+s \geqq N}\left|f^{(r, s)}(0,0)\right| H_{r, s} \leqq \sum_{r+s \geqq N}[H(\tau(f)+\varepsilon)]^{r+s} .
$$

Let $\rho=H(\tau(f)+\varepsilon)$ and $K=\sum \sum_{r+s<N}\left|f^{(r, s)}(0,0)\right| H_{r, s}$. Then (3.3) is less than

$$
K+\sum_{r=0}^{\infty} \sum_{s=0}^{\infty} \rho^{r+s}=K+\frac{1}{(1-\rho)^{2}}
$$

and the convergence of (3.2) follows.

Proof of Theorem 2. Let $S=\left\{\left(m_{j}, n_{j}\right): j=1,2,3, \cdots\right\}$ be an infinite sequence such that

$$
H=\lim _{j \rightarrow \infty} H_{m_{j}, n_{j}}^{1 /\left(m_{j}+n_{j}\right)}
$$

and

$$
H_{m_{j}, n_{j}}^{1 /\left(m_{j}+n_{j}\right)} \geqq H_{p, q}^{1 /(p+q)}
$$

for all $p$ and $q$ such that $p+q \leqq m_{j}+n_{j}$. For each $(r, s) \in S$, let $\alpha=\alpha(r, s)$ and $\beta=\beta(r, s)$ be matrices with entries on $|z|=1$ such that

$$
\left|A_{r, s}(0,0 ; \alpha, \beta)\right|=H_{r, s} \text {. }
$$

Let 


$$
P_{r, s}\left(z_{1}, z_{2}\right)=\frac{A_{r, s}\left(z_{1}, z_{2} ; \alpha, \beta\right)}{A_{r, s}(0,0 ; \alpha, \beta)}
$$

and

$$
Q_{r, s}\left(z_{1}, z_{2}\right)=P_{r, s}\left(\frac{z_{1} H_{r, s}^{1 /(r+s)}}{H}, \frac{z_{2} H_{r, s}^{1 /(r+s)}}{H}\right)
$$

Then $Q_{r, s}(0,0)=P_{r, s}(0,0)=1$, and

$$
Q_{r, s}^{(j, k)}\left(\frac{H \alpha_{j k}}{H_{r, s}^{1 /(r+s)}}, \frac{H \beta_{j k}}{H_{r, s}^{1 /(r+s)}}\right)=0 \quad(j<r, k<s),
$$

Moreover, (2.6) implies

$$
Q_{r, s}\left(z_{1}, z_{2}\right)=\sum_{p=0}^{r} \sum_{q=0}^{r} \frac{A_{r-p, s-q}\left(0,0 ; R_{p q}(\alpha), R_{p q}(\beta)\right) H_{r, s}^{(p+q) /(r+s)}}{A_{r, s}(0,0 ; \alpha, \beta) H^{p+q}} \frac{z_{1}^{p} z_{2}^{q}}{p ! q !}
$$

and

$$
\begin{aligned}
& \left|\frac{A_{r-p, s-q}\left(0,0 ; R_{p q}(\alpha), R_{p q}(\beta)\right) H_{r, s}^{(p+q) /(r+s)}}{A_{r, s}(0,0 ; \alpha, \beta) H^{p+q}}\right| \\
\leqq & \frac{H_{r-p, s-q} H_{r, s}^{(p+q) /(r+s)}}{H_{r, s} H^{p+q}} \leqq \frac{H_{r, s}^{(r-p+s-q) /(r+s)} H_{r, s}^{(p+q) /(r+s)}}{H_{r, s} H^{p+q}}=\frac{1}{H^{p+q}},
\end{aligned}
$$

since $(r, s) \in S$. Therefore $Q_{r, s}$ is majorized by

$$
\varphi\left(z_{1}, z_{2}\right)=\sum_{p=0}^{\infty} \sum_{q=0}^{\infty} \frac{1}{H^{p+q}} \frac{z_{1}^{p} z_{2}^{q}}{p ! q !} ;
$$

$\varphi\left(z_{1}, z_{2}\right)$ is an entire function of exponential type $1 / H$. The sequence $\left\{Q_{m_{j}, n_{j}}\right\}$ is therefore uniformly bounded on compact sets. Extract a uniformly convergent subsequence from $\left\{Q_{m_{j}, n_{j}}\right\}$ and let $F$ denote the limit function. Then $F$ is entire, $F(0,0)=1$, and $\tau(F) \leqq 1 / H$. Since $F^{(j, k)}$ is the uniform limit of a subsequence of $\left\{Q_{m_{j}, n_{j}}^{(j, k)}\right.$, then (3.4) implies that $F^{(j, k)}$ has a zero in $\left\{\left|z_{1}\right|=1,\left|z_{2}\right|=1\right\}$. The expansion (1.5) implies that $F$ has exponential type exactly $1 / H$, and this completes the proof.

4. The Whittaker Constants $W$ and $\mathscr{W}$. We have already seen that $\mathscr{W}<W$. The following result provides a precise relationship between $\mathscr{W}$ and $W$, and a determination of $W$ different from [3] and [1].

THEOREM 3.

$$
\begin{gathered}
\limsup _{m+n \rightarrow \infty} H_{m, n}^{1 /(m+n)}=1 / \mathscr{W}, \\
\liminf _{m+n \rightarrow \infty} H_{m, n}^{1 /(m+n)}=1 / W .
\end{gathered}
$$


Proof. The first equation is a consequence of Corollary 1 and Corollary 2. To prove the second, we require the use of the Gončarov polynomials $G_{n}\left(z ; z_{0}, \cdots, z_{n-1}\right)$ and the sequence

$$
H_{n}=\max \left|G_{n}\left(0 ; z_{0}, \cdots, z_{n-1}\right)\right| \text {. }
$$

If $m$ is a positive integer, the defining relation (1.4) implies

$$
A_{m, 0}(0,0 ; \alpha, \beta)=-\sum_{p=0}^{m-1} \frac{A_{p, 0}(0,0 ; \alpha, \beta) \alpha_{p, 0}^{m-p}}{(m-p) !} .
$$

In comparing (4.1) with (1.1), one sees that

$$
A_{m, 0}(0,0 ; \alpha, \beta)=G_{m}\left(0 ; \alpha_{00}, \alpha_{10}, \cdots, \alpha_{m-1,0}\right) .
$$

It follows that $H_{m, 0}=H_{m}$ and, similarly, $H_{0, m}=H_{m}$. By Lemma 3 and (1.2), we have

$$
\begin{aligned}
& H_{m, n}^{1 /(m+n)} \geqq\left(H_{m, 0} H_{0, n}\right)^{1 /(m+n)}=\left(H_{m} H_{n}\right)^{1 /(m+n)} \\
> & \left(\frac{.16}{W^{m+n}}\right)^{1 /(m+n)}=\frac{(.16)^{1 /(m+n)}}{W} .
\end{aligned}
$$

Therefore

$$
\liminf _{m+n \rightarrow \infty} H_{m, n}^{1 /(m+n)} \geqq 1 / W
$$

In the other direction,

$$
\liminf _{m+n \rightarrow \infty} H_{m, n}^{1 /(m+n)} \leqq \liminf _{m+0 \rightarrow \infty} H_{m, 0}^{1 /(m+0)}=\lim _{m \rightarrow \infty} H_{m}^{1 / m}=1 / W,
$$

and this completes the proof.

Using (2.10) and the estimate $W<.7378$, one easily obtains an interesting bound on $\mathscr{W}$. For all $r$ and $s$, we have

$$
H_{r, s} \leqq(2 / \log 2)^{r+s}<\left(\frac{2}{\log 2} \frac{.7378}{W}\right)^{r+s}<\left(\frac{2.13}{W}\right)^{r+s}
$$

and therefore

$$
W>\mathscr{W} \geqq \frac{W}{2.13}
$$

Some remarks should be made relative to stating the above results in terms of $k$ complex variables, $k>2$. For $j=1,2, \cdots, k$, let $\alpha^{(j)}=\left(\alpha_{n_{1}, n_{2} \cdots, n_{k}}^{(j)}\right)$ denote a $k$-parameter sequence of complex numbers. The recursion relation corresponding to (1.4) is

$$
A_{0,0, \ldots 0}\left(z_{1}, z_{2}, \cdots, z_{k}\right)=1
$$




$$
\begin{aligned}
& A_{n_{1}, n_{2}, \cdots, n_{k}}\left(z_{1}, z_{2}, \cdots, z_{k}\right) \\
& =\frac{z_{1}^{n_{1}} \cdots z_{k}^{n_{k}}}{n_{1} ! \cdots n_{k} !}-\sum_{p_{1}=0}^{n_{1}} \cdots \sum_{p_{k}=0}^{n_{k}} \\
& \times \frac{A_{p_{1}, \cdots, p_{k}}\left(z_{1}, \cdots, z_{k}\right)\left[\alpha_{p_{1}}^{(1)}, \cdots, p_{k}\right]^{n_{1}-p_{1}} \cdots\left[\alpha_{p_{1}, \cdots, p_{k}}^{(k)}\right]^{n_{k}-p_{k}}}{\left(n_{1}-p_{1}\right) ! \cdots\left(n_{k}-p_{k}\right) !}
\end{aligned}
$$

where $p_{1}+\cdots+p_{k}<n_{1}+\cdots+n_{k}$.

The numbers $H_{n_{1}, \ldots, n_{k}}$ are also defined in the obvious way and we have

$$
\begin{aligned}
H_{n_{1}, \cdots, n_{k}} & \geqq H_{m_{1}, \cdots, m_{k}} H_{n_{1}-m_{1}, \cdots, n_{k}-m_{k}}, \\
H_{n_{1}, \cdots, n_{l}, 0, \cdots, 0} & =H_{n_{1}, \cdots, n_{l}} .
\end{aligned}
$$

The definition of $\mathscr{W}_{k}$, the Whittaker constant in $k$ complex variables, is analogous to the definition of $\mathscr{W}$ in $\S 1$. Apart from notational difficulties, it is a direct extension of the above results to see that

$$
\lim \sup H_{n_{1}, \ldots, n_{k}}^{1 /\left(n_{1}+\cdots+n_{k}\right)}=1 / \mathscr{W}_{k}
$$

and

$$
\lim \inf H_{n_{1}, \ldots, n_{k}}^{1 /\left(n_{1}+\cdots+n_{k}\right)}=1 / W .
$$

If $1 \leqq l \leqq k$, we also have

$$
\lim \sup H_{n_{1}, \ldots, n_{l}, 0, \ldots, 0}^{1 /\left(n_{1}+\ldots+n l\right)}=1 / \mathscr{W}_{l}
$$

and

$$
\lim \inf H_{n_{1}, \ldots, n_{l}, 0, \cdots, 0,0}^{1 /\left(n_{1}+\ldots+n l\right)}=1 / W,
$$

and it follows that $\mathscr{W}=\mathscr{W}_{2} \geqq \mathscr{W}_{3} \geqq \mathscr{W}_{4} \geqq \cdots$.

\section{REFERENCES}

1. J. D. Buckholtz, The Whittaker constant and successive derivatives of entire functions, Journal of Approximation Theory, (3) 2 (1970).

2. M. M. Džrbašjan, On the integral representation and expansion in generalized Taylor series of entire functions of several complex variables, Mat. sb. (N.S.), (41) 83 (1957), 257-276 (Amer. Math. Soc. Translations, (2) 32 (1963), 289-310).

3. M. A. Evgrafov, The Abel-Gončarov interpolation problem, Gosvdavstr. Izdat. Tehn.Teor. Lit., Moscow, 1954.

4. S. S. Macintyre, An upper bound for the Whittaker constant, London Math. Soc. J., 22 (1947), 305-311.

5 . - On the zeros of successive derivatives of integral functions, Trans. Amer. Math. Soc., 67 (1949), 241-251.

Received October 30, 1970.

Virginia Polytechnic Institute and State University 


\section{PACIFIC JOURNAL OF MATHEMATICS}

\section{EDITORS}

H. SAMELSON

Stanford University

Stanford, California 94305

C. R. Hовву

University of Washington

Seattle, Washington 98105
J. DUGUNDJI

Department of Mathematics

University of Southern California

Los Angeles, California 90007

RICHARD ARENS

University of California

Los Angeles, California 90024

\section{ASSOCIATE EDITORS}
E. F. BECKENBACH
B. H. NeumanN
F. WOLF
K. YoSHIDA

\section{SUPPORTING INSTITUTIONS}

UNIVERSITY OF BRITISH COLUMBIA

CALIFORNIA INSTITUTE OF TECHNOLOGY

UNIVERSITY OF CALIFORNIA

MONTANA STATE UNIVERSITY

UNIVERSITY OF NEVADA

NEW MEXICO STATE UNIVERSITY

OREGON STATE UNIVERSITY

UNIVERSITY OF OREGON

OSAKA UNIVERSITY

UNIVERSITY OF SOUTHERN CALIFORNIA
STANFORD UNIVERSITY

UNIVERSITY OF TOKYO

UNIVERSITY OF UTAH

WASHINGTON STATE UNIVERSITY

UNIVERSITY OF WASHINGTON

AMERICAN MATHEMATICAL SOCIETY CHEVRON RESEARCH CORPORATION NAVAL WEAPONS CENTER 


\section{Pacific Journal of Mathematics}

\section{Vol. 38, No. $1 \quad$ March, 1971}

Bruce Alan Barnes, Banach algebras which are ideals in a Banach algebra ..... 1

David W. Boyd, Inequalities for positive integral operators............... 9

Lawrence Gerald Brown, Note on the open mapping theorem .............. 25

Stephen Daniel Comer, Representations by algebras of sections over Boolean

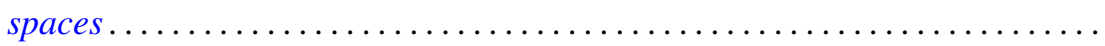

John R. Edwards and Stanley G. Wayment, On the nonequivalence of

conservative Hausdorff methods and Hausdorff moment sequences ........

P. D. T. A. Elliott, On the limiting distribution of additive functions $(\bmod 1) \ldots \ldots$

Mary Rodriguez Embry, Classifying special operators by means of subsets

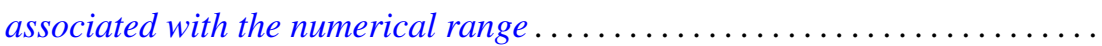

Darald Joe Hartfiel, Counterexamples to a conjecture of G. N. de Oliveira ......

C. Ward Henson, A family of countable homogeneous graphs...............

Satoru Igari and Shigehiko Kuratsubo, A sufficient condition for

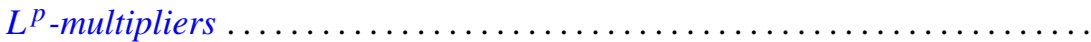

William A. Kirk, Fixed point theorems for nonlinear nonexpansive and

generalized contraction mappings............................

Erwin Kleinfeld, A generalization of commutative and associative rings ...... 95

D. B. Lahiri, Some restricted partition functions. Congruences modulo $11 \ldots \ldots 103$

T. Y. Lin, Homological algebra of stable homotopy ring $\pi *$ of spheres ....... 117

Morris Marden, A representation for the logarithmic derivative of a meromorphic function...........................

John Charles Nichols and James C. Smith, Examples concerning sum properties for metric-dependent dimension functions . .

Asit Baran Raha, On completely Hausdorff-completion of a completely

Hausdorff space.

M. Rajagopalan and Bertram Manuel Schreiber, Ergodic automorphisms and affine transformations of locally compact groups..........

N. V. Rao and Ashoke Kumar Roy, Linear isometries of some function

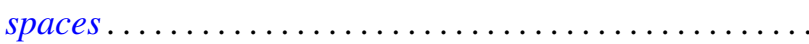

William Francis Reynolds, Blocks and F-class algebras of finite groups

Richard Rochberg, Which linear maps of the disk algebra are multiplicative ...

Gary Sampson, Sharp estimates of convolution transforms in terms of decreasing

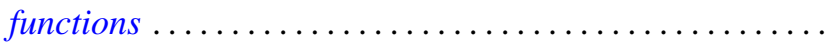

Stephen Scheinberg, Fatou's lemma in normed linear spaces

Ken Shaw, Whittaker constants for entire functions of several complex

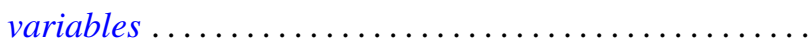

James DeWitt Stein, Two uniform boundedness theorems................ 251

$\mathrm{Li} \mathrm{Pi} \mathrm{Su,} \mathrm{Homomorphisms} \mathrm{of} \mathrm{near-rings} \mathrm{of} \mathrm{continuous} \mathrm{functions} \mathrm{.} \mathrm{.............} 261$

Stephen Willard, Functionally compact spaces, $C$-compact spaces and mappings of minimal Hausdorff spaces....................... 